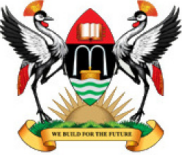

East African School of Higher Education Studies \& Development
Makerere Journal of Higher Education

ISSN: 1816-6822; 4(2) (2013) 159 - 167

DOI: http://dx.doi.org/10.4314/majohe.v4i2.3

(C) The Author(s) 2013

Reprints \& permission: EASHESD

http://ajol.info/majohe

\title{
Social Cultural Factors Influencing Women's Participation in Sports as Perceived by Female Students of the University of Ilorin
}

\author{
Ogidan Rotimi Joshua $^{1, *}$, Onifade Olasunkanmi Adeoye ${ }^{1}$, Ologele Ibrahim $^{1}$ \\ ${ }^{1}$ University of Ilorin [*Corresponding author: rjogidan@gmail.com]
}

\begin{abstract}
This study investigated the socio-cultural factors influencing women's participation in sports as perceived by female undergraduates in the University of Ilorin. Two hundred female undergraduate students residing in school halls of residence were involved in the study. These were selected using simple random sampling. A twenty-two item questionnaire based on socio-cultural factors influencing female participation in sports was administered to the respondents. The findings were that culture, family background, religion, peer grouping and gender influence females' participation in sports. In view of this, it was recommended that government should encourage participation in sports by providing scholarship and other incentives to female athletes who excel in any sports competition while mass media should organize enlightenment programmes that will mitigate the socio-cultural factors hindering women's involvement in sports.
\end{abstract}

Keywords: Student support services; Sports participation; Gender.

\section{Introduction}

Despite immense contributions of women to national development in Africa, they still face a number of difficulties that limit their potentials in promoting personal and collective development. Ladan (2009) opined that, for many years, society maintained a greater degree of sports competition for boys than for girls. In recent years, there have been many change in women's participation in sports, but the rate of changes have been found to be extremely low. Adler (2008) explained that, today as in the past most female members of the society have fewer opportunities in life compared to their male counterparts as they are expected to run a home and bring up children. Women have less free time in their choice of leisure activities and they are more restricted than males. Over a 
long period of time, women have demanded changes in society to give them equal status with men. Social changes have gradually given women greater opportunities to plan their own lives. Nevertheless, the battle for equal opportunities with men is still being fought.

The low rate of women involvement in sports is not due to lack of interest in sports by them. Instead, it is due to the long history of direct and indirect forms of discrimination and stereo-typing that women have to contend with (Adeyanju, 2011). The sport for all movement started in the mid-1970s in Europe. It was a concept being adopted to achieve a long term objective by the council of Europe, it was aimed at encouraging the population at large to become more active while it also proclaimed the message that sports are not for the talented few. Almost twenty years later, participation in sports and recreation are justified on the assumption that they serve as mediums for developing desirable attitudes and behaviour that are essential for one's own wellbeing. Sports for all was an attempt to extricate sport from domination by the privilege few and to declare it as an entitlement for everybody in an egalitarian society. This means that, sports for all implies equal opportunities for participation for both males and females, irrespective of age, political affiliation, gender, race or religion. While this was considered to be important and the ideal, it has proved difficult to achieve in reality, particularly in relation to women (Okey, 2011).

In contrast to the expectation of sport for all, women experience role conflict and this is reflected in the attitude of the general public regarding female athletic participation in Nigeria. Women's participation in sport in Nigeria has for a long time been relatively low compared with men due to differential treatment based on socio-cultural roles and expectations. Consequently, the traditional images of gender in Nigeria have often worked against women's participation in sport. This perhaps, extensively reduces already existing opportunities that are available for women in sports. An analysis of those actively involved in sports in Nigeria indicates that men constitute the greater number either as players, coaches, or as administrators. In spite of Nigeria's ethnic, culture and religious diversity, a constant theme seems to run through the society as regards the traditional place of women; her traditional place is in the home. Her ideal role is associated with child bearing, rearing and housekeeping. Nigeria is therefore is classified as a society where cultural values predominate in all activities (Adeyanju, 2011).

Women have faced barriers that have discouraged their progress in the level of participation in sport. Amuche (2004) demonstrated that, throughout history, men have controlled sport, used it for their own purposes and shaped it to fit their abilities. Consequently, fewer numbers of women have participated in sporting activities than men. Ikhioya (1999), reported that, women in Nigeria universities were not active sport participants. According to him, these women 
did not regard sport as conducive to their physical wellbeing. Nigerian society still experiences significant gender inequality in sports, despite recent international class performances by women sprinters and football players in national teams. This inequality can visibly affect the opportunities for women to participate in sport, thereby limiting their sport experiences. Ikhioya (1999), further showed that in most communities in Nigeria especially rural ones, cultural beliefs and attitudes had strong influences on low participation of women in sports. Besides, organization of sporting activities in most communities are usually focused on combative sports, such as boxing, wrestling, archery and shooting. Men are major participants in such sports which tend to discriminate against women. Sports participation and nonparticipation are influenced by several factors which are related to and basically hinged on socio-cultural background. The survival of any activities like sports is regarded as a function of socio-cultural characteristics which prevails in an organization. Sports therefore as an institutionalized social phenomenon depends largely for its continuing existence on the favourable support it receives from cultural and social forces.

It was stated by Adeyanju (2011) that, psycho-social and cultural factors which exert pressure on women through the immediate family, community, religion, media, peer groups and other sources of socialization to reinforce expected behaviour and teaching of gender roles. Sports is an exemplary activity which focuses attention on the gender influence by allowing for the comparison of innate against learned factors. Sports, traditionally, is defined as a male domain. Excellence in sports is an attribute cherished for men while it is seen as a distraction for women rather than an element of healthy living.

Ikulayo (1998) observed that, most developing countries, including Nigeria, have not experienced rapid changes in women's active participation in sports compared to their more developed counterparts. This is due to a number of socio- cultural factors such as religion, parent, culture, peer group, gender role, massmedia etc on religion aspect for example in northern Nigeria where majority are muslims. The Islamic religion and social expectations for public behaviour influences the choice of women in this part of the country to participate actively in sport. Adeyanju (2011) observed that, religious attitude as regards the free association of men and women and the exposure of parts of the body especially that of women, is a major constraints to female participation in sports.

Ikulayo (1998) stated that, most societies in the late twentieth century still believed that a woman's place was in the kitchen, in care of children and in managing domestics chores. When women are at home, they may not have adequate space or time to fully participate in sports. Yan and Thomas (2005), reported that, cultural expectations shape children's physical activity patterns and gender differences in their motor performance. Adler (2008) indicated that, 
parents' reactions and expectations towards their children create the messages or concepts of children's sex role stereotypes in physical activity. This report portends that, sex role stereotype can affect sport experiences of women.

\subsection{Statement of the Problem}

Human beings live in a world where inequality reigns. This inequality manifests itself in various spheres in Nigeria and it affects the womenfolk greatly. Inequality exists in political, social, education and sports spheres; where women are being discriminated against based on their gender. Adeyanju (2011) observed that, the low involvement of women in sports is not due to the lack of interest in sports by women. It is due to the long history of direct, and indirect forms of discrimination and stereo-typing as well as many other problems that women have to contend with. Women's participation in sports in Nigeria has for a long time been relatively low compared with men due to differential treatment attached to socio-cultural factors i.e parent, religion, culture, gender, peer group, mass media etc. Ikhioya (1999), reported that, women in Nigerian universities were not active sport participants. According to him, women did not regard sport as conducive to their physical well being. Changes can however be noticed following the advent of western education accompanied by exposure across culture and ethnic background. Review of available literature revealed that there is paucity of study on influence of social cultural factors on sport participation among students in the University of Ilorin. The present study therefore, investigated social cultural factors influencing female participation in sports as perceived by female undergraduates of the University of Ilorin. The study was carried out to provide information on some socio-cultural factors influencing women participation in sports. It is hoped that the findings of the study would benefit sport administrator, parents, students and society at large as regards involvement of women in sports.

\subsection{Research Questions}

The following research questions were posed to guide conduct of the study:

1. Will cultural belief influence female participation in sports?

2. Will parents influence female participation in sports?

3. Will religion influence female participation in sports?

4. Will peer group influence female participation in sports?

5. Will gender influence female participation in sports? 


\subsection{Research Hypotheses}

1. Cultural beliefs of respondents will not significantly influence female participation in sports.

2. Parental role on respondents will not significantly influence female participation in sports.

3. Religion role on respondents will not significantly influence female participation in sports.

4. Peer group will not significantly influence female participation in sports.

5. Gender-role will not significantly influence female participation in sports.

\section{$2 \quad$ Methodology}

The research method adopted for the study is descriptive research design. The research population comprised female undergraduate students of University of Ilorin residing in halls of residence. The halls of residence were considered appropriate for easy accessibility and to obtain honest and spontaneous responses from the respondents. The estimated population of female undergraduate students residing in halls of residence were 1,120 . Two hundred students were sampled using random sampling technique across three (3) purposively selected halls of residence in the University (Abuja, Zamfara \& Lagos hostels). Data were collected using a researcher's made questionnaire titled socio-cultural factors influencing female participation in sports (SIFPS).

The forms were distributed to the respondents with the support of Students Affairs Division of the University. The instrument administered had two sections; Section A elicited demographic data while Section B sought information on respondents' socio-cultural factors as related to culture, parents, religions, peer group and gender. The instrument was validated by three lecturers in the Department of Human Kinetics and Health Education, University of Ilorin, Nigeria. The reliability of the instrument was conducted with the use of split-half procedure. A correlation coefficient of $.75 \mathrm{r}$ was obtained was considered to be high enough for the study. Inferential statistic of chi-square was used to analyze the results of data collected.

\section{$3 \quad$ Finding and Discussion}

The findings of the study are summarized in Table 1. 
Table 1: Social Cultural Factors Influencing Women's Participation in Sports

\begin{tabular}{llllll}
\hline Factor & Df & Alpha level & Critical level & Calculated $\mathbf{X}^{2}$ & $\begin{array}{l}\text { Decision on null } \\
\text { hypothesis }\end{array}$ \\
\hline Culture & 12 & 0.05 & 21.03 & 30.5 & Rejected \\
Parent & 9 & 0.05 & 16.92 & 32.2 & Rejected \\
Religion & 9 & 0.05 & 16.92 & 30.1 & Rejected \\
Peer group & 9 & 0.05 & 16.92 & 45.3 & Rejected \\
Gender & 12 & 0.05 & 21.03 & 78.2 & Rejected \\
\hline
\end{tabular}

Table 1 shows the calculated chi-square and critical level of socio-cultural factors (variables) that influence female participation in sports. All the variables have the calculated chi-square that was greater than the critical value, showing that all the variables were upheld because they influence female participation in sports.

The table revealed that, cultural belief had chi-square value of 30.5 that was higher than the critical value of 21.03. This means that, majority of the respondents agreed that cultural beliefs of respondents had significant influence on female participation in sports. This finding is in consonance with the findings of Adeyanju (2011) who pointed out that, physiological myths is strong, in which many people still believe that physical exercise by women has a detrimental effect on their reproductive organs and women lose their feminity through active participation in sports. Ikhioya (1999) also showed that, in most communities in Nigeria, particularly in the rural areas, cultural beliefs and attitudes had strong influences on low participation of women in sports.

The findings of the study also revealed that parental influence had significant impact on female participation in sports. This was in agreement with Adler (2008) who indicated that, parents' reactions and expectations towards their children create the message or concepts of children's sex role stereotypes in physical activity. This notion can affect sport experiences of women. Hums (2008) had also reported that, parents respond negatively to females than the males participation in sport. This shows that while parents tend to permit males, they object to females participation in sport for sex stereotypic reasons. Similarly, males are more encouraged to participate in active pursuits of sports outside the home while female are reinforced for engaging in activities within the confines at home.

Findings of this study shows that, religion had significant influence on female participation in sports. This is a corroboration to the finding of Money (2002) who pointed out that, in France and many other countries, the Catholic and Protestant Churches opposed women's participation in sports. Similarly, it is a common belief by Nigerians that Islam discouraged adherents of Islamic religion from sport participation because of the specific types of dress that are prescribed for the participants. 
Furthermore, results in the table above indicated that, peer-group have significant influence on female participation in sports. This is in support of NIXON (2000), who conducted an investigation on why college women enter into athletic participation. It was reported by the researcher that female peer group served as the most significant agent of socialization into sports participation from childhood through adulthood. The study further stated that, peer group constituted important agent by stimulating members' interest in sporting activities. During adulthood, the most influential predictor was found to be the peer group accompanied by a significantly decreased influence exerted by the family. From the foregoing therefore, it is obvious to state that the roles played by peer group to influence female participation in sports is immeasurable.

Results in the table displayed above indicated that, gender had significant influence on female participation in sports. This finding corroborates the finding of Gunwa (1993) who observed that, the female gender in the modern Nigerian society had been valued so much for her succulent, dedicated body and good looks which are assumed to be incompatible with the physical vigor, strength and force supposedly required for sport competition. It is not surprising to find out that males are channeled into sports, while female are not. Moreover, anytime women participate in sports, it is usually limited to a few sports out of the total ranges of sports that open to men.

\section{Conclusions and Recommendations}

The outcome of this study have identified some of the socio-cultural factors that influence female participation in sports i.e. culture, parent, religion, peer group and gender. The results have laid credence to Adeyanju (2001) who submitted that, the low involvement of women in sports is not due to the lack of interest in sports by women. It is due to the long history of direct, and indirect forms of discrimination and stereo-typing as well as many other problems that women have to contend with. Arising from findings of this study, the following are recommended:

- Government at all levels should create enabling environment for unfettered participation of women in sports and its management.

- Government should encourage female participation in sport by providing scholarship and other incentives to female athletes who excel in any sporting competition.

- Mass media should organize enlightenment programme that will eliminate all socio-cultural biases against female participation in sporting activities.. 
- The private organizations and individuals in the society should support the government at all levels to provide and improve sports facilities and equipment in schools so as to enable more participation in sports by both sexes.

\section{References}

Adeyanju, F.B. (2011). Women and sports in Nigeria: problems and prospects in the $21^{\text {st }}$ century. Available at http://www.onlinenigeria.com.accessed on 27-12-2011.

Adler, J. (2008) Social changes and women in African sports. A Publication of Journal of social sciences. 2(1), 50-53.

Amuche, F. (2004) Towards effective organization of sports in Nigeria. Journal of Nigeria Association for Physical and Health Education and Recreation. 3(2), 5-7.

Esiobu, G.O. (2011). Enhancing gender equality and lifelong skills acquisition of pre-services teacher through research in education. Journal of Research in education 1(1),10-12.

Gunwa, G.A. (1993). Sports Participation for the advancement of women: Strategies and Action Plan. Edited Proceedings; Nigerian Association of Women in Sports Conference, Lokoja.

Hums, M.A. (2008). Roles and status of women in sport management. Journal of the International Council for Health, Physical Education, Recreation, Sport and Dance, 34 (2), 12-13.

Ikhioya O.S.A. (1999). Socializing young females towards sport and Olympic ideals. Journal of the International Council for Health. Physical Education, Recreation, Sport and Dance. 35(4):37-40.

Ikulayo, P.B. (1998). Psychological Issues in Female Participation in Sport. Journal of the International Council for Health, Physical Education, Recreation, Sport and Dance, 34 (3), 60-62.

Isreal O.O. (2006). Girl-child education as a development challenge in the common-wealth West African sub-region. African Journal of Historical Sciences in Education, 2(1), 17-19.

Ladan, B. (2009). Psychology of women's participation in competitive sports. Journal of physical and Health Education. 8(4), 20-23.

Money, E.O. (2002). A study of the perception of female athletes towards female coaches. Journal of Sport Science and Medicine, 3(2), 94-96.

Nixon, J.E. (2000). Human adaptation to physical activities. International Journal of Physical Education 1 (3), 8-10. 
Okey C. O. (2011). Social situations affecting the sporting experience of working class women in Nigeria: a challenge to sport for all. Available at http://www.la84foundation.org.accessed on 26-12-2011.

Yan, J. H., Thomas, J. R. (2005). Parents assessment of physical education and sports, 37 (2), 38-40.

Social cultural factors influencing female participation in sports as perceived by female undergraduates of the University of Ilorin. 